\title{
ENTRE O ANALÍTICO E O PRESCRITIVO: DISPUTAS EM TORNO DOS DIREITOS HUMANOS ${ }^{1}$
}

\author{
Raquel Kritsch ${ }^{2}$
}

\begin{abstract}
Resumo
A temática dos direitos humanos constitui hoje relevante e disseminada matéria de pesquisa. Inúmeros estudiosos das mais variadas correntes de pensamento e filiações políticas têm se debruçado sobre 0 assunto com enorme paixão - não sem razão. Tal movimento é exatamente o que tem dificultado ao leitor leigo distinguir, no debate acerca dos direitos humanos, argumentos analíticos de abordagens de caráter mais propositivo. 0 objetivo deste artigo é mostrar àqueles que estão se introduzindo neste tema de pesquisa pelo menos dois diferentes níveis em que a literatura de área aborda a temática dos direitos humanos. Para tanto, utilizase dois exemplos de tratamento do fenômeno: de um lado, uma explicação de natureza analítica-descritiva; e, de outro lado, uma abordagem mais prescritivanormativa. 0 intuito de tal percurso é permitir ao estudante compreender as diferentes funções de um e de outro tipo de manejo do instrumental teóricoconceitual de área.
\end{abstract}

Palavras-chave: Direitos humanos. Teoria política. Análise. Prescrição.

\footnotetext{
${ }^{1}$ Dedico este artigo a Raissa, Márcia e Matheus, que muito me inspiraram. Agradeço a leitura crítica dos membros do GETEPOL-CNPq bem como dos colegas Luís Antonio de Souza, Maria José de Rezende, Adrián G. Lavalle e Martha Ramírez-Gálvez.

${ }^{2}$ Docente junto ao Departamento e ao Programa de Pós-Graduação em Ciências Sociais da Universidade Estadual de Londrina. Publicação vinculada ao Projeto de Pesquisa "Direitos humanos universais e Estados nacionais: fundamentos históricos e problemas teóricos II", financiado pelo CNPq, e desenvolvido junto ao Grupo "Estudos em Teoria Política" (GETEPOLCNPq).End. eletrônico: kritsch@uel.br
} 


\title{
BETWEEN THE ANALYTICAL AND THE PRESCRIPTIVE: DISPUTES ABOUT HUMAN RIGHTS
}

\begin{abstract}
The theme of human rights is considered a relevant and spread field of research. Many scholars of the most varied currents of thought and political affiliations have been working on the subject with great passion - not without reason. This movement is exactly what has hindered the lay reader to distinguish, in the debate about human rights, analytical arguments of more purposeful approaches. The aim of this paper is to show those who are introducing in this topic of research, at least two different levels in which the literature of area addresses the issue of human rights. We also use two examples for the treatment of the phenomenon: on one hand, an explanation of analytical-descriptive nature, and on the other hand, a more prescriptive-normative approach. The aim of this course is to enable students to understand the different functions of one and other type of handling of the theoretical-conceptual tools of the area.
\end{abstract}

Keywords: Human rights. Political theory. Analysis. Prescription.

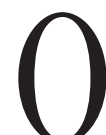
uando o assunto é direitos humanos, é freqüente encontrarmos, ao debruçarmo-nos sobre a bibliografia de área, textos que abordam o tema a partir de dicotomias aparentemente opostas, como particularismo e untrersalismo, Estados nacionais e direitos humanos, soberania estatal e governança global, indivíduo e comunidade política, etc. Também não é incomum verificarmos que seus autores amiúde não conseguem definir-se com clareza em favor de um ou outro lado: geralmente, constata-se a necessidade e premência da defesa dos direitos humanos, especialmente naquelas formações políticas que carecem de um Estado de direito consolidado; mas conclui-se, ao mesmo tempo, que é extremamente difícil - quiçá improvável - fazer com que se cumpram as normas do direito internacional dos direitos humanos onde não há uma formação política de tipo estatal, capaz de centralizar a força e a aplicação da justiça e de tornar seus comandos vinculantes (cf. DONNELLY, 1998, p. 320-1; KRASNER, 1999, p. 140; FORSYTHE, 2006, p. 24; ARCHIBUGI, 2005, p. 29; HELD, 1995, p. 270; BROWN, 1999, p. 116; WALZER, 2003, p. 135-6).

Transformações em curso no mundo atual, por sua vez, constituem elementos concretos que terminam por acentuar a tendência dos cientistas de 
perceber o mundo contemporâneo a partir de "novos paradigmas", decretando 0 "fim", o "ocaso" ou mesmo a fraqueza e/ou fragilidade das velhas instituições (cf. p. ex. FUKUYAMA, 1992; HUNTINGTON, 1997). Entre tais transformações se pode mencionar, por exemplo, a gradativa ampliação do ideário e dos instrumentos dos direitos humanos às mais variadas comunidades do planeta, impulsionada fortemente por instituições internacionais como as Nações Unidas e seus braços, e por cartas como a Declaração e Programa de Ação da Conferência de Viena (1993); uma certa "flexibilização" da soberania dos Estados 3 , os quais vêm aceitando mais e mais jurisdições compartilhadas no nível internacional; ou ainda o fluxo cada vez mais intenso de pessoas que residem e/ou trabalham em "comunidades de destino" distintas de suas "comunidades de origem".

Tais afirmações muitas vezes radicais e pouco matizadas, que não raro dispõem de grande força retórica, especialmente em virtude de seu apelo ao "novo", acabam produzindo, na argumentação dos estudiosos das ciências humanas, certa confusão conceitual que dificulta o trabalho tanto do leitor quanto do analista: é freqüente, nestes autores, a sobreposição de - quando não a confusão mesmo entre - dois níveis distintos: o analítico e o prescritivo-normativo ${ }^{4}$. Um problema que se acentua sobremaneira quando o assunto é direitos humanos no mundo contemporâneo.

É curioso notar que parte significativa da literatura acerca dos direitos humanos no campo ciência política, direcionada às relações internacionais, tende a operar predominantemente no nível analítico. Ou seja, trata-se de abordagens

\footnotetext{
${ }^{3}$ A expressão é de S. Benhabib (2002, p. 179), que, por sua vez, inspira-se na noção de "flexible citizenship", cunhada por A. ONG (1999), para falar da cidadania no mundo contemporâneo.

${ }^{4}$ Os dois termos serão tomados aqui em seu sentido comum, dicionarizado. 0 vocábulo "analítico" indicará aquilo que procede por análise, isto é, por determinação e descrição dos elementos e/ou princípios que se organizam em uma teoria. Neste senso, aproxima-se da noção de "conhecimento positivo", isto é, de conhecimento evidente, verdadeiro (para o saber daquele momento histórico), de caráter seguro, baseado nos fatos e na experiência. Já o lexema "normativo" servirá para designar o conhecimento que enuncia e/ou prescreve um tipo concreto ou fórmula abstrata do que deve ser, que admite um juízo de valor, que determina o que é correto, bom, ou ainda aquilo que se recomenda praticar. Para os fins deste artigo, portanto, chamar-se-á "abordagem analítica ou descritiva" àquelas teorias que procuram explicar um fenômeno tal como é, mais do que como deveria ser; enquanto a denominação "abordagem prescritiva ou normativa" ficará reservada àquele tipo de teorização que repousa sobre compromissos éticos e/ou coisas ou comportamentos a serem recomendados, valorizados ou desejados. Entretanto, é preciso ter claro que esta diferenciação é utilizada aqui como mero recurso metodológico. Para este uso, cf. p. ex. Stefan Weber (2003, p. 327-8).
} 
que se ligam mais a "teorias positivas", no sentido de que procuram trabalhar com aspectos históricos, conceituais, jurídicos, etc., do processo de consolidação dos direitos do homem, do Estado nacional ou da soberania; e freqüentemente são associadas ao chamado realismo político, como é o caso de R. Jackson, S. Krasner e D. Miller, entre outros. Tais teorias cientificistas ou positivas tendem a operar primordialmente com base em dados concretos e argumentos "objetivos", isto é, demonstráveis e verificáveis, sustentando que os fenômenos políticos devem ser analisados e/ou descritos - jamais prescritos -, independentemente da opinião dos seus endereçados.

Entretanto, fora deste eixo, pode-se localizar outra grande "matriz" interpretativa, não raro associada a alguma forma de idealismo político, que tende a enfatizar os aspectos normativos e prescritivos presentes nas doutrinas bem como nos "novos paradigmas teóricos". Neste eixo, portanto, os temas do Estado, da soberania, dos direitos humanos, etc., geralmente são pensados não tanto no quadro das estruturas conceituais existentes, e sim muito mais no plano do "devir", do "vir a ser" histórico, como é o caso de D. Archibugi, A. Linklater, D. Held, C. Taylor, e outros. Trata-se assim de autores que, embora (re)conheçam a evidência analítica, a presença do Estado e da soberania e suas consequiências para o ideário dos direitos humanos, propõem e sustentam uma abordagem prescritiva da questão dos direitos humanos e sua relação com Estados nacionais. Isto é, trata-se de autores que têm uma abordagem normativa do assunto, segundo a qual o pensador político pode e deve formular normas ou padrões de correção aos endereçados da política; e também pode e deve lutar para que estes padrões vinguem como normas ou preceitos de comportamento político. Neste sentido, pode-se sustentar que vários deles têm em comum a pretensão de repensar e/ou refundar as bases da teoria política sob novos pressupostos 5 .

Assim, num caso, o da abordagem analítica-descritiva, trabalha-se com termos "verificáveis" empiricamente e com um arsenal analítico acumulado pela ciência daquela área; noutro, o da abordagem normativa-prescritiva, opera-se no nível da construção ética e política, que sempre implica rever o aparato conceitual disponível e modificá-lo. Provavelmente, a melhor maneira de reconhecer e

\footnotetext{
${ }^{5}$ Do mesmo modo que um dia os autores clássicos que viveram sob o absolutismo, como p. ex. J. Locke, formularam teorias normativas sobre o governo constitucional - isto é, teorias que reviam os conceitos políticos disponíveis à época, procurando prescrever um novo tipo de relação entre os agentes políticos, a carta constitucional e a autoridade estatal -, as quais, mais tarde, acabaram se tornando uma prática concreta, uma "realidade", um fato empiricamente constatável.
}

ENTRE O ANALÍTICO E O PRESCRITIVO... 
explic(it)ar estas duas abordagens seja procurando mostrar como elas podem aparecer no debate, tarefa que se buscará levar a cabo de maneira modesta neste artigo.

\section{ELEMENTOS ANALÍTICOS NO DEBATE DA CIÊNCIA POLÍTICA}

Krasner (2001, p. 20), um reconhecido estudioso do Estado moderno e da soberania, afirma que a "soberania westfaliana" se assenta em dois princípios: a territorialidade e a exclusão de atores externos das estruturas de autoridade internas. Segundo ele, o Estado existe em territórios específicos sobre os quais as autoridades políticas internas constituem os únicos árbitros do comportamento legítimo. A soberania westafaliana é violada, continua, quando atores externos influem sobre ou determinam as estruturas de autoridade domésticas.

Sem dúvida, esta é uma definição da noção de soberania com a qual a esmagadora maioria dos cientistas políticos concordaria. E mais: ela tem o mérito de pôr em relevo os principais traços políticos que a constituem. No entanto, a idéia moderna de soberania, como já se documentou fartamente na literatura de área, reparte com o político um aspecto jurídico de relevo, que faz dela uma noção com dupla natureza: ela consiste também, e de maneira primordial, no poder de jurisdição exclusiva sobre um determinado território ${ }^{6}$. Esta é, sem dúvida, uma das marcas definidoras da soberania na era moderna - uma definição sacramentada na teoria política desde pelo menos Jean Bodin (BODIN, 1994, p. 56; 1986, I, 10, p. 308-9).

Tal formulação configurou uma novidade: não era assim que se exercia 0 mando antes da chamada modernidade política. Como se sabe, o mundo feudal funcionava com jurisdições compartilhadas entre diferentes níveis de governança: havia a jurisdição do barão, a do conde, a do rei, a do imperador, a do papa, e assim por diante. Ou seja, a aplicação da justiça era descentralizada e se realizava em múltiplas esferas de jurisdição (STRAYER, s/d, p. 18-32; BARTELSON, 1995, p. 105-7). Tal cenário foi transformado pela modernidade política quando se forjou um novo "mecanismo" de centralização da feitura das leis e da execução da justiça, ao qual Hobbes chamou de Deus mortal (HOBBES, 1988, p. 227), o

\footnotetext{
${ }^{6}$ Para o aprofundamento desta questão, cf. Kritsch (2005, p. 375-99).
} 
Leviatã moderno, e que a tradição de pensamento político iria denominar mais tarde Estado moderno soberano.

Ora, se a soberania moderna tem a sua mais completa tradução na idéia de jurisdição exclusiva (isto é, de imposição de normas e comandos vinculantes pela autoridade legítima) sobre um determinado território — uma definição portanto fundamentalmente jurídica —, a noção de Estado, por sua vez, vai ser sintetizada inicialmente na fórmula que o define como aquele poder que centraliza o monopólio da força num determinado território (definição que vai aparecer, p. ex., em Maquiavel e Bodin). Num primeiro momento, portanto, o que se reconhece é um Estado definido basicamente pela possibilidade de aplicação exclusiva da força nos limites de um dado território (BARTELSON, 1995, p. 29-30, 41). A esta formação política, a tradição de pensamento político chamou Estado territorial moderno, modelo que vingou na Europa ocidental até o século XVIII.

Com as revoluções "burguesas" do século XVII e XVIII, vemos nascer uma idéia nova, que seria traduzida no conceito de Nação, e que iria se acoplar à idéia de Estado territorial, significando que o monopólio da força sobre aquele território se exerce agora também sobre um ator novo, o povo (ou os nacionais), a quem se vai atribuir a potencialidade de constituir a única sede legítima do poder. Isto é, o povo passa a ser entendido agora como a fonte da soberania e, portanto, como fonte de todo direito. Assim, além de se exercer sobre um determinado território, a soberania estatal agora se vincula também a um povo específico, sede de todo poder legítimo. A este novo atributo do poder soberano pensadores clássicos como Locke ou Rousseau nomearam soberania popular ou soberania do povo. E o Estado agora é redefinido como Estado nacional (ou Estado-Nação), fundando a "trindade" povo-Estado-território, como ironiza Arendt (1989, p. 263) - fenômeno que marcaria profundamente a história européia nos séculos XIX e XX.

Tais idéias modernas encontram na formulação weberiana a sua mais conhecida e repetida versão: aquela segundo a qual o Estado é definido como uma comunidade humana organizada que reivindica deter o monopólio do uso legítimo da violência dentro dos limites de um determinado território (WEBER, 1996, p. 56). Uma definição que combina, portanto, força com direito, violência administrada e legitimidade. Como procura mostrar Kelsen (1990, p. 210, 230), o Estado, assim definido, consiste numa técnica de organização social, isto é, de organização legítima da força coletiva (ou poder soberano), que tem no território 
o limite da validade espacial do direito e no povo o limite de validade pessoal do direito.

Assim, pode-se constatar que, nos primórdios do processo de formação e desenvolvimento histórico e teórico destes conceitos fundantes da ciência política, duas noções que guardavam relativa independência conceitual entre si, Estado (outrora identificado a regnum, civitas, polis, etc.) e soberania (atributo expresso em outras épocas por termos similares, como plenitudo potestatis, maxima potestas, dominium), serão apropriadas pelos autores e pensadores modernos e (re)definidas de maneira a formarem um par conceitual que vincula de modo umbilical poder e direito, força e legitimidade, monopólio da violência e jurisdição exclusiva (KRITSCH, 2002, p. 35-48).

Se a noção de Estado soberano consiste, como grande parte do arsenal teórico das ciências sociais, numa construção fundamentalmente histórica, específica de um certo tempo e lugar, leia-se, da Europa ocidental na era moderna, isto não nos impede de verificar que, para além de mero "argumento acerca da autoridade estatal" (FORSYTHE, 2006, p. 20), a idéia de soberania funda práticas específicas e concretas; práticas que, ao longo dos séculos, passaram a determinar comportamentos. Um fenômeno que se liga justamente à história desta vinculação a um arranjo particular entre política e direito na modernidade política - movimento que permitiria à teoria política formular, um pouco depois, a idéia de Estado de direito como base para os direitos humanos.

Isto porque só se pode falar em Estado de direito quando poder político e direito passam a constituir, no pensamento ocidental moderno, duas faces de uma mesma moeda, na qual interagem estrutura jurídica e poder político, ordenamento legal e violência administrada. Ou seja, quando o campo de referência do poder político se traduz na produção e na aplicação de normas jurídicas (ou leis), as noções de Estado e direito passam a estar umbilicalmente vinculadas ${ }^{7}$. E esta é outra grande novidade da modernidade política no Ocidente.

\footnotetext{
${ }^{7}$ Como é que este processo de acomodação entre força e direito foi se traduzindo na vida prática dos povos? De um lado, a consolidação do Estado moderno abrigou e fomentou a centralização e a aplicação do direito naquele que era o seu âmbito específico, a saber, a administração da esfera pública. 0 Estado moderno fomentou e abrigou a centralização e a aplicação do direito ao monopolizar entre suas funções a tarefa de (im)por aos seus membros (mais tarde, cidadãos) um conjunto de regras vinculantes, igualmente válidas para todos. De outro lado, ao monopolizar a feitura da lei e a administração da justiça, o Estado passou a incorporar paulatinamente estas regras legais - e, com isso, também a lógica jurídica - ao seu próprio mecanismo de funcionamento. Este
} 
Força e lei constituíram os dois instrumentos de cada um desses processos que, vinculados, vieram a caracterizar o moderno Estado de direito. Por isso, inclusive, é que Weber pode sustentar que, no Estado moderno, a legitimidade do poder vai estar vinculada à sua legalidade (isto é, a legitimidade do poder vai depender do respeito aos limites impostos pela lei). Assim, denomina-se esta formação política Estado de direito justamente porque ela constitui um poder derivado de um ordenamento jurídico reconhecido como tal, que se exerce segundo regras previamente estabelecidas (WEBER, 1980, p. 122-30).

Ora, essa maneira de pensar o Estado - definido desde Kelsen como um ordenamento jurídico -, tem implicações teóricas e práticas relevantes para se pensar a questão da relação entre direito e política. Implicações que se refletem na problemática da implementação dos direitos humanos no mundo de hoje. Como podemos, então, compreender o modo pelo qual os direitos do homem se ligam a estas construções histórico-teóricas? Uma maneira de fazê-lo é procurando entender como a história desta noção se vincula ao conceito moderno de Estado soberano.

Os direitos do homem (ou direitos humanos), nasceram, historicamente, como é de domínio público, no Renascimento, com a afirmação e consolidação: $1^{\circ}$ ) da idéia de que 0 ser humano seria portador de uma dignidade que lhe é intrínseca (como se lê p. ex. em Oratio de hominis dignitate, de Pico della Mirandola, 1486 [1942]); $2^{\circ}$ ) de que a pessoa humana desfruta de um valor em si, o que a tornaria fonte de valores e princípios; e $3^{\circ}$ ) mais tarde, da noção de indivíduo. Estas idéias iriam permitir, entre outras inovações de peso, a afirmação do princípio segundo o qual os indivíduos são portadores de direitos inalienáveis, em virtude de seu pertencimento ao gênero qua humano.

Os direitos do homem, como é sabido, iriam se definir nas lutas contra os absolutismos que povoaram o território europeu sobretudo nos séculos XV, XVI e XVII. Inicialmente, chamou-se este conjunto de garantias legais conferidas aos indivíduos de direitos civis (ou liberdades subjetivas de ação). Com o surgimento e afirmação da idéia de povo como sede da soberania, nos séculos XVII-XVIII, passou-se a afirmar, especialmente no século XIX, que estes indivíduos também deteriam direitos políticos, determinados pelo seu nascimento e pertencimento

movimento produziu uma teia complexa de normas jurídicas que regulam, entre outras coisas, tanto um conjunto de poderes que são exercidos no âmbito da estrutura do Estado quanto as relações dos seus membros entre si em diferentes níveis. 
àquela comunidade outrora territorialmente e, agora, politicamente definida, a Nação.

0 que, então, passa a definir o ser cidadão de uma república ou de uma nação na modernidade política? Pode-se dizer, sem grandes ressalvas, que, no mundo moderno, ser cidadão significa, em primeiro lugar, deter e exercer um conjunto de direitos que protegem a existência e o desenvolvimento de cada um dos membros desta comunidade política (ou nação); e isto se dá por meio da garantia de direitos e liberdades aos indivíduos. Donde se pode depreender a noção de sujeito portador de direito.

Em segundo lugar, a cidadania, tal como pensada pelos clássicos da política, permite a estes cidadãos participar do processo de decisão (ou de autodeterminação) política da comunidade, o que supõe, portanto, a existência de uma comunidade cultural, lingüística e social de referência. Neste sentido, a cidadania está associada ao compartilhamento de língua, usos e costumes por uma coletividade (ou nação), bem como a um sentimento de pertencimento e de que os seus membros repartem um destino comum. Donde se afirma uma outra noção importante, a de soberania do povo. 0 entrelaçamento destas duas idéias, a de indivíduo portador de direitos iguais diante da lei e a de pertencimento a uma comunidade política fundada na soberania popular, formaram assim 0 sustentáculo da idéia moderna de cidadania (AUDARD, 2003, p. 249).

Partindo destes processos históricos característicos da modernidade política e desta base analítica comum a vários ramos das ciências humanas (direito, filosofia, história, ciência política, etc.), Habermas vai afirmar que as noções de soberania do povo e de direitos humanos foram as duas respostas históricas oferecidas pela teoria política para o problema da legitimação das ordens politicas estatais.

Em “Acerca da legitimação com base nos direitos humanos", ele explica que o Estado moderno (que é uma comunidade jurídica particular) se caracteriza pelo fato de que a potência política se constitui na modernidade sob a forma do direito positivo (isto é, daquele direito que está regulamentado e que coage). Por esta razão, as ordens políticas (o Estado e seus órgãos), que demandam legitimação, alimentam-se da reivindicação de legitimidade do direito (HABERMAS, 2001a, p. 143-4). Habermas se refere aqui àquela vinculação histórica entre poder político e direito, descrita acima. 
0 direito, por sua vez, continua o pensador alemão, reclama não só reconhecimento fático, mas reclama também merecer este reconhecimento. Ou seja, o direito coage - traço que reparte com a política -, mas também reivindica ser digno de ser reconhecido, ser legítimo. Habermas lembra que Kant já havia chamado a atenção para o fato de que, no Estado moderno, a legalidade repousa num duplo fundamento: as leis de um Estado são legítimas não só porque geram normas capazes de coagir os indivíduos à obediência; mas elas também são legítimas, sobretudo e principalmente, porque os cidadãos obedecem tais leis por respeito, isto é, obedecem pela adesão voluntária ao comando do soberano ${ }^{8}$ (IDEM: 146). Como já ensinara Kant, este é o único modo pelo qual se pode exigir obediência jurídica de pessoas moralmente responsáveis, autônomas.

Habermas não só endossa a visão kantiana como também procura explicar a tensão entre a facticidade e a legitimidade do direito, quando se adota esta perspectiva: aqui, o ponto crucial é entender que, no campo da moral, a autonomia é, por assim dizer, monolítica; já no campo do direito positivado, a autonomia surge sob uma dupla forma: a da autonomia pública e a da autonomia privada. (HABERMAS, 1997, p. 298; cf. tb. 2004, p. 298). E isto acontece, esclarece o autor, porque

0 universo moral, [que se encontra como que] liberado das suas fronteiras no espaço social e no tempo histórico, estende-se a todas as pessoas naturais nas complexidades das suas histórias de vida; a própria moral [estende-se] até a proteção da integridade de [sujeitos] particulares plenamente individualizados. Em contrapartida, uma comunidade jurídica, sempre localizada no espaço e no tempo, protege a integridade dos seus membros apenas na medida em que [eles] aceitem 0 status, gerado artificialmente, de portadores de direitos subjetivos (1997, p. 296 - grifos do autor, minha tradução).

Ou seja, o campo moral pode ser estendido a todos os seres humanos e, neste sentido, é concebido como universal(izável). Já um Estado constitucional é limitado por fronteiras espaciais e temporais e só pode garantir proteção aos seus integrantes se eles acatam o estatuto de indivíduos portadores de direitos.

\footnotetext{
${ }^{8}$ Nos termos de Habermas (2001a, p. 146): "A validade de uma norma jurídica afirma que 0 poder estatal garante ao mesmo tempo positivação jurídica legitima e execução judicial fática. 0 Estado deve garantir ambos, por um lado, a legalidade do comportamento no sentido de um [sic] seguimento satisfatório da lei, caso necessário, forçado com base em sanções, e, por outro, uma legitimidade das regras que torna a todo o momento possível o cumprimento de uma norma por 'respeito à lei'”.
} 
Daí, inclusive, a tensão, que comumente se verifica na literatura especializada, entre o sentido universal dos direitos humanos e sua validade legal,tema que será retomado adiante.

Justamente para abordar como esse processo foi construído ao longo da história política do Ocidente, bem como para explicar a especificidade do problema, Habermas retoma os clássicos com o intuito de mostrar que o problema da legitimação das ordens políticas estatais recebeu por parte da teoria política aquelas duas respostas históricas já mencionadas, que aparecem nas noções de soberania do povo e de direitos do homem.

Segundo ele, a aparente tensão existente desde então na teoria política entre direitos do homem e soberania popular, isto é, entre o indivíduo como sede do direito e o povo (ou a coletividade) como fonte do direito legítimo -, vem sendo abordada de maneira inadequada, como se se tratasse de posições excludentes. Enquanto alguns pensadores políticos enfatizam a precedência da autonomia pública dos cidadãos do Estado (ou a soberania popular), outros afirmam a primazia da autonomia privada dos cidadãos da sociedade (ou direitos humanos) em relação à vontade do povo (HABERMAS, 1997, p. 298; cf. tb. 2004, p. 298-9).

Estas duas posições, no entanto, não são excludentes, como podem parecer à primeira vista, e sim complementam-se, esclarece Habermas: a soberania popular, de um lado, garante um procedimento - o procedimento de tipo democrático - que fundamenta a expectativa de resultados legítimos (isto é, ela garante a autonomia pública ou política dos cidadãos do Estado, que se traduz na sua capacidade de auto-determinação). Já os direitos do homem clássicos, por outro lado, garantem aos cidadãos da sociedade a vida e a liberdade privada, ou seja, garante-lhes âmbitos de ação para seguirem os seus planos de vida pessoais e suas concepções de bem (ou sua autonomia privada) (IDEM: 298-9):

Em um caso, os direitos humanos deveriam a sua legitimidade ao resultado da autocompreensão ética e da autodeterminação soberana de uma coletividade política; no outro caso, eles deveriam construir limites legítimos a partir deles mesmos que vedassem à vontade soberana do povo a usurpação das esferas de liberdade subjetivas intocáveis. Contra esses unilateralismos complementares deve-se perseverar no fato de que a idéia dos direitos humanos - o direito fundamental kantiano sobre as mesmas liberdades subjetivas de ação - nem se impõem simplesmente ao legislador soberano como um limite externo, nem deve ser instrumentalizada como um requisito funcional para seus objetivos (HABERMAS, 2001a, p. 147). 
Habermas reconhece, contudo, a anterioridade lógica do segundo termo (direitos do homem) sobre o primeiro (soberania do povo), já que as pessoas do direito só podem ser autônomas, como ensinou Kant, quando lhes é permitido, no exercício de seus direitos de cidadãos do Estado, compreenderem-se como autores desses mesmos direitos aos quais, como endereçados, elas devem prestar obediência (1997, p. 298), de modo que são os direitos do homem que possibilitam a práxis de autodeterminação dos cidadãos (IDEM: 300). Aliás, não há direito algum sem a autonomia privada dos sujeitos do direito, emenda ele adiante (IDEM: 301).

Com isso, sustenta o autor, os direitos do homem fundamentam uma soberania das leis legítimas a partir de si mesmas, fundada tanto no valor da pessoa humana enquanto tal quanto na sua dignidade intrínseca - duas idéias que podem ser universalizáveis. Ora, o direito positivado (o direito humano modificável), precisa se legitimar sob esses dois pontos de vista normativos: como um instrumento para a proteção igualitária tanto da autonomia privada quanto da autonomia política dos indivíduos (2001a, p. 146). E o elemento que permite essa integração, nas sociedades modernas, prossegue ele, é a Constituição (ou ordenamento jurídico), a qual permite ligar a criação de um sistema de direitos ao exercício da soberania popular (IDEM: 147).

Com base nesta argumentação, Habermas (1997, p. 300) sustenta então a existência de um nexo interno entre direitos do homem e soberania popular. Tal nexo consiste no fato de que os direitos do homem possibilitam a institucionalização jurídica de uma prática política do uso público das liberdades comunicativas. Isto é, possibilitam a institucionalização jurídica das condições de comunicação para a formação da vontade política racional (2001a, p. 148) - ou das condições sob as quais os cidadãos, ao desempenharem seu papel de cidadãos do Estado, podem fazer uso da sua autonomia pública (1997, p. 301).

Ou seja, Habermas assume aqui que não existe direito sem a autonomia privada das pessoas (sem agentes portadores de direitos): sem os direitos clássicos à liberdade de ação, sem os direitos do homem, não haveria um meio para a institucionalização jurídica daquelas condições sob as quais os cidadãos podem participar da práxis de auto-determinação (isto é, da prática da soberania popular). Isto permite a ele dizer que a autonomia pública e a autonomia privada - a soberania do povo e os direitos do homem - se pressupõem mutuamente.

Este raciocínio o conduz a outro nexo imediato: aquele existente entre democracia e Estado de direito. A oposição entre democracia (ou o primado da 
soberaniapopular) e constitucionalismo (com asuaênfase nos direitos individuais) é excessiva, dado que, como já se mostrou, cada um dos termos é dependente do outro. Assim, segundo ele, o nexo interno entre democracia e Estado de direito está no fato de que os cidadãos do Estado só podem utilizar adequadamente a sua autonomia política (ou pública) se eles forem, enquanto cidadãos da sociedade, suficientemente independentes graças à sua autonomia privada garantida de maneira igualitária. 0 reverso também é verdadeiro: eles só vão poder usufruir da sua autonomia privada se, como cidadãos do Estado, fizerem um uso adequado da sua autonomia política. De onde se conclui que os direitos fundamentais liberais e os direitos políticos da cidadania são indivisíveis. Daí, inclusive, a denominação Estado democrático de direito (HABERMAS, 2001b: 149-50).

Mas Habermas não escapa da conclusão inevitável: nesta constelação característica do 0cidente, afirma, os direitos humanos se apresentam a nós hoje com uma cabeça dupla - uma "cabeça de Janus" -, voltada ao mesmo tempo para a moral e para o direito. E explica: como normas morais, os direitos humanos têm um sentido universal e se dirigem a todos os seres humanos. Daí falarmos, no nível normativo, de direitos humanos universais. Como normas jurídicas (ou regras positivas), no entanto, prossegue Habermas seguindo Arendt, eles protegem as pessoas somente na medida em que elas pertencem a uma determinada comunidade jurídica (geralmente, um Estado nacional). E é isso o que provoca uma tensão entre o sentido universal dos direitos humanos e sua efetivação (que é local); ou entre o seu âmbito moral e o seu aspecto legal (2001a, p. 149-50).

Ou seja, no nível analítico, Habermas reconhece que ainda não há, no mundo de hoje, alternativa a esta imbricação entre soberania territorial, cidadania de base nacional, Estado de direito e democracia - que, como se procurou mostrar, é fruto de um desenvolvimento histórico específico, característico, sobretudo, das formações políticas centro-européias. Analiticamente, tudo parece indicar que enquanto os direitos humanos forem pensados e afirmados dentro do quadro dos elementos, da lógica e das estruturas do Estado-Nação moderno, não há como torná-los universais de fato, para além do nível de uma reivindicação moral. Enquanto perdurar esta "engrenagem" que vincula ordenamento jurídico fundado no indivíduo portador de direitos, formações estatais delimitadas por fronteiras territoriais e cidadania democrática de base nacional, não será factível garantir de maneira eficaz o ideário dos direitos humanos sobre todo o planeta. 
Este parece ser o "estado da arte" no debate atual, quando se pretende abordar a temática dos direitos humanos a partir de uma perspectiva analítica, sustentada no conhecimento acumulado disponível ao meio científico nos dias de hoje. Tal constatação não impede, contudo, que inúmeros pensadores se debrucem sobre a questão, buscando formular alternativas teóricas e práticas que permitam abandonar a camisa de força que envolve a relação da reivindicação e afirmação de direitos humanos universa(lizáve)is e sua efetivação, geralmente dependente, em última instância, de Estados nacionais soberanos.

Tal alternativa só está disponível, por enquanto, no nível normativoprescritivo, o que termina por gerar muita confusão conceitual entre aqueles que estão se introduzindo na temática dos direitos humanos, ou ainda entre pesquisadores cujo foco principal não é a teoria política e/ou a teoria geral do direito e do Estado. Esta "mistura" - legítima, é preciso deixar bem claro - de níveis distintos, analítico e normativo, na abordagem de um fenômeno polêmico como os direitos humanos pode ser muito mal assimilada pelos leitores quando não vem acompanhada de um aviso claro, capaz de sinalizar que, dali para frente, trata-se da construção de um devir, e não propriamente de uma explicação analítica. Como podemos então detectar a passagem de um eixo para outro?

\section{ELEMENTOS PRESCRITIVOS NO DEBATE DA CIÊNCIA POLÍTICA}

Habermas é um exemplo de pensador político que trata o assunto dos direitos humanos nestes dois níveis; mas ele tem ao menos o cuidado de separar sua análise histórica e teórica de sua interpretação normativa-prescritiva a respeito da questão dos direitos humanos, mesmo que seja apenas por meio da introdução de um novo sub-tópico ("II. A autocrítica do Ocidente"), como é o caso em "Acerca da legitimação com base nos direitos humanos" (2001a, p. 143-63), texto que foi utilizado até aqui para tratar de sua perspectiva analítica.

Outro sinal de uma tal transição referencial pode ser percebido no tempo verbal, que, em boaparte dos escritos normativos e/ou prescritivos, deixa de aparecer no pretérito ou no presente, e passa a ser conjugado, com enorme freqüência, especialmente em língua portuguesa, no futuro do pretérito, expressando-se por meio de vocábulos como "deveria", "poderia", "seria", "haveria", "mostraria", e outras tantas formas de construção do devir histórico. Também a defesa de uma 
forma de organização social, política e/ou cultural que percebemos somente como um desideratum, mas ainda não como uma realidade prática, perceptíveis em ideologias como cosmopolitismo, comunismo ou globalismo, entre muitas outras, podem nos auxiliar na interpretação do registro teórico deste ou daquele autor.

Seyla Benhabib, por exemplo, procurando levar adiante as reflexões de Arendt sobre o "direito a ter direitos", a partir de algumas categorias conceituais de Habermas, busca construir uma nova interpretação, de caráter abertamente prescritivo, capaz de dar conta das questões da cidadania e dos direitos humanos diante de uma suposta "constelação pós-nacional". Segundo Benhabib (2002, p. 179), o sistema do Estado-Nação, caracterizado pelo "mundo interno" da política territorialmente delimitada e pelo "mundo externo" das relações estrangeiras diplomáticas e militares, estaria sendo reconfigurado de maneira profunda.

Baseando-se nas análises de D. Held, a autora explica que estaríamos vivendo hoje uma "desterritorialização da política, do governo e da lei". Num contexto mundial que é cada vez mais volátil e mais mutável, o Estado nacional teria se tornado pequeno demais para lidar com os vários problemas que surgem no mundo globalizado, ao mesmo tempo em que tem se mostrado incapaz, por ser muito vasto, de conter as aspirações identitárias de movimentos sociais locais e regionalistas. A territorialidade teria se convertido então numa delimitação anacrônica das funções materiais do Estado e das identidades culturais dos povos diante das transformações promovidas pela globalização econômica, financeira, cultural e política (BENHABIB, 2002, p. 179-80).

Isto é, as funções do Estado e as identidades culturais dos povos já não se limitam mais, nos dias de hoje, às fronteiras físicas dos seus territórios?. Segundo ela, tal processo de globalização estaria gerando uma mudança também no conceito de cidadania democrática: ele estaria fomentando o surgimento de um discurso mundial de direitos humanos; e também o crescimento de redes de solidariedade transnacionais entre culturas e regiões em torno de questões comuns, como os imigrantes ou a energia nuclear. Estes movimentos indicariam o surgimento de novas modalidades de ações e de coordenações políticas e éticas em um novo mundo:

\footnotetext{
${ }^{9}$ Em suas palavras: "À medida que a economia global mina o poder dos Estados nacionais para definir políticas redistributivas e alcançar justiça econômica domesticamente, fontes alternativas de hegemonia cultural são oferecidas por meio da inter e da transnacionalização da cultura, pelo movimento das pessoas através de fronteiras estatais porosas e pela ascensão de meios de comunicação globais." (2002, p. 180 - minha tradução).
} 
adentramos um mundo no qual as democracias liberais deverão dar conta do fim da cidadania unitária. Movimentos multiculturais são tanto uma manifestação destas transformações quanto atores [players] na modelagem do futuro. (...) [reivindicações multiculturalistas] advogam uma pluralização das identidades culturais; elas demandam o descentramento da uniformidade administrativa e a criação de hierarquias legais e jurisdicionais múltiplas; elas exigem a devolução do poder democrático a regiões ou grupos; e elas dão as boas vindas ao enfraquecimento do vínculo entre residência territorial ininterrupta e responsabilidades cidadãs (BENHABIB, 2002, p. 181 minha tradução).

Em The rights of others (2004, p. 1), Benhabib explica, seguindo as pegadas de Arendt, que as migrações transnacionais permitem-nos enxergar que 0 mundo tem experimentado novas modalidades de pertencimento; e que o antigo vínculo fundado na cidadania nacional já não é mais adequado como critério regulador da comunidade política. Para Arendt (1989, p. 262), como é sabido, a cidadania nacional se configurava como a principal garantia de proteção dos direitos humanos aos indivíduos. Portanto, era fundamental, para ela, que os Estados nacionais assegurassem os direitos do homem (ou o primordial "direito a ter direitos") a todos os seus membros, sem restrições de qualquer natureza (étnica, religiosa, sexual, etc.).

Este quadro detectado por Arendt, no entanto, estaria se alterando a passos largos: para Benhabib, as migrações transnacionais, tão intensas em nossos dias, servem justamente para destacar aquilo que a autora chama de "paradoxo da legitimidade democrática" (2004, p. 43-44), constitutivo das democracias modernas. Isto é, indicam a contradição existente entre, de um lado, as reivindicações da autodeterminação soberana, e, de outro lado, a adesão aos princípios dos direitos humanos universais. Tal processo seria ainda mais acentuado pelo desenvolvimento acelerado da globalização e pela crescente reafirmação dos princípios universais dos direitos humanos, ao mesmo tempo em que se reafirmam identidades particulares de uma determinada etnia, língua ou nacionalidade, partindo da idéia do pertencimento a um povo soberano (IDEM: 46-7).

Ela sustenta que, mesmo que tal paradoxo possa nunca ser resolvido completamente nas democracias contemporâneas, os seus impactos podem ser minimizados por meio de uma renegociação e reiteração (reiteration) dos compromissos duais com os direitos humanos e com a autodeterminação soberana. Argumenta que uma "adesão democrática" de indivíduos e/ou grupos 
não tem necessariamente de ser dirigida à estrutura dos Estados nacionais existentes. Pelo contrário: quando a instituição da cidadania encontra-se em processo de desagregação, como no mundo atual, podem emergir - e ela crê, a partir do exemplo da UE, que estejam emergindo - espaços subnacionais bem como supranacionais para adesão e ações democráticas, nos quais os indivíduos devem se promover como entes políticos existentes (2002, p. 178-9 e 184).

Tempos depois, ao fazer a defesa de um federalismo cosmopolita, Benhabib (2004, p. 54-5) reafirmaria a importância de se respeitar as reivindicações das diversas comunidades democráticas, incluindo suas compreensões distintivas referentes à cultura e à lei, fortalecendo, com isso, as normas de uma justiça cosmopolita. Segundo ela, o problema não é tanto uma questão de distribuição justa de recursos em escala global, como querem os teóricos neokantianos da justiça internacional, e sim muito mais o da filiação política justa. Negligenciar assuntos (re)definidores da noção de cidadania, como o da imigração, sustenta, teria como conseqüência a não percepção de que o controle político e a proteção das fronteiras do Estado contra estrangeiros, refugiados e asilados constitui a "pedra fundamental do modelo Estadocêntrico".

Assim, para que se possa pensar a questão da justiça em relação à filiação política, é preciso reconhecer alguns aspectos cruciais: o direito moral dos refugiados e dos asilados a uma primeira adesão; um regime de fronteiras porosas para os imigrantes; uma lei contra as desnacionalizações e contra a perda dos direitos de cidadania; e a reivindicação de todo o ser humano ao direito a ter direitos, isto é, de ser reconhecido como uma pessoa legal, possuidora de certos direitos inalienáveis, independente da sua filiação política. A condição de forasteiro, insiste ela, não deveria privar ninguém de usufruir de seus direitos fundamentais (2004, p. 220-1).

Para Benhabib, os desenvolvimentos empíricos do mundo atual não só indicam tendências que revelam a desagregação da cidadania, mas também prenunciam transformações da soberania democrática ${ }^{10}$. 0 desafio que a autora se

\footnotetext{
${ }^{10}$ Segundo Benhabib (2004, p. 178 e 206-8), a soberania democrática estaria embasada em três ideais normativos: no de que o povo é tanto o autor como o sujeito das leis; no ideal de um demos unificado; e na idéia de um território fechado em si mesmo e autóctone em relação ao governo do demos. Tais idéias, escreve ela, não são mais sustentáveis tanto por motivos normativos quanto empíricos. A unidade do demos não deve ser entendida como algo harmonioso, mas sim como um processo de auto-constituição, por meio de lutas mais ou menos conscientes de inclusão e exclusão. Além disso, a concepção da auto-suficiência territorial se choca com interdependência dos povos ao
} 
coloca, portanto, é o de pensar um regime internacional que separe o direito a ter direitos da condição nacional do indivíduo ${ }^{11}$. Ora, separar os direitos do homem da condição nacional de membro de um Estado constitui uma possibilidade teórica e prática que, como ela mesma reconhece, coloca-se para nós hoje, por enquanto, apenas no nível normativo.

Por isso, diante da nova configuração do mundo globalizado, é preciso desenvolver uma concepção de direito cosmopolita capaz de abarcar os dois pólos da legitimidade dos entes políticos democráticos: os princípios de direitos universalistas e as reivindicações da autodeterminação dos povos. Assim, o que deve guiar os princípios normativos do pertencimento, ou melhor, a nova política do pertencimento, é, na visão dela, uma complexa negociação entre pertencimento pleno, voz democrática e direito de residência territorial. Pois os direitos cosmopolitas criariam uma rede de obrigações e de imbricações em torno da soberania, exigindo uma redefinição da cidadania de base nacional. (BENHABIB, 2004, p. 24 e 20).

A construção de tal cidadania cosmopolita passa, no raciocínio desta autora, pelo que ela chama de democratic iterations, isto é, por "iterações democráticas", que se caracterizam por constituir processos complexos de argumentação, deliberação e aprendizado públicos por meio dos quais reivindicações universalistas de direitos são contestadas e contextualizadas, invocadas e revogadas por instituições políticas e jurídicas bem como na esfera pública de democracias liberais. Tais iterações democráticas seriam capazes de mostrar como os compromissos para com as normas constitucionais e internacionais capazes de transcender o contexto podem ser negociados com a vontade de maiorias democráticas (IDEM: 19).

Deste modo, os princípios normativos do pertencimento devem ser guiados, a seu ver, por uma abordagem que parta: $1^{\circ}$ ) de uma ética discursiva - entendida enquanto uma "metanorma" (Habermas) - que pressuponha os princípios do respeito moral universal e da reciprocidade igualitária ${ }^{12}$; e $2^{\circ}$ ) de uma teoria

redor do mundo, processo que teria sido acelerado pelo fenômeno da globalização (IDEM: 217).

${ }^{11}$ Como afirma Benhabib (2004, p. 4), "A doutrina da soberania estatal, que por tanto tempo blindou as decisões de naturalização, cidadania e desnacionalização do escrutínio pelas cortes tanto constitucionais quanto internacionais, tem de ser desafiada."

${ }^{12}$ Benhabib (2004, p. 13) define "respeito universal" como o reconhecimento dos direitos de todos os seres capazes de fala e ação de serem participantes do diálogo moral; e "reciprocidade igualitária" como o princípio que estipula que, nos discursos, cada qual deva ter os mesmos direitos a vários atos de fala, de iniciar novos tópicos e de demandar justificação das pressuposições da conversação. 
normativa da democracia deliberativa (IDEM: 12). Daí, inclusive, a idéia de que a nova política do pertencimento, como dito acima, diria respeito, a seu ver, à complexa negociação entre pertencimento pleno, voz democrática e residência territorial.

Benhabib, evidentemente, não está sozinha: inúmeros autores de relevo tanto na ciência política quanto na filosofia política têm oferecido teorias normativas similares para fundamentar suas reivindicações de que é preciso pensar o novo desenho do mundo que está por surgir. Mesmo Habermas, um autor bastante empenhado em oferecer uma abordagem positiva das estruturas e elementos que, em sua visão, caracterizam o mundo contemporâneo, não deixa de se posicionar no debate e de propor rumos e formas para o novo modelo políticojurídico-institucional em construção. Também ele se assume um defensor (e, até certo ponto, propagador) de um certo tipo de cosmopolitismo. Para Habermas (2001a, p. 150-1), p. ex., a passagem de uma ordenação Estadocêntrica, isto é, de uma ordem política e jurídica centrada primordialmente nos Estados nacionais, para uma ordem cosmopolita pós-nacional pode ser parcialmente fundamentada na adesão, pela grande maioria dos Estados mundiais, à carta dos direitos humanos da ONU.

Por isso, para que os anseios difusos dos "cidadãos mundiais" possam ganhar alguma materialidade, sugere o frankfurtiano a propósito da discussão sobre a legitimidade das intervenções humanitárias, pode-se até mesmo evocar uma política ofensiva pelos direitos humanos naqueles lugares onde eles não estão sendo observados, na medida em que um Estado [constitucional] mundial (Weltstaat) - isto é, um Estado mundial capaz de ligar a todos em vínculo de cidadania, unindo-nos num "patriotismo constitucional" que teria como laço de fidelidade (ou de lealdade) o assentimento à carta dos direitos humanos da ONU - ainda não existe (2001b, p. 34-5 e 37).

Habermas (2001a,p. 150-2) atésemostraconscientedos riscos eurocentristas da sua argumentação e reconhece os problemas da passagem de uma ordem de Estados nacionais para outra cosmopolita. Mas, diante de uma situação mundial marcada pela instabilidade constante e pela realidade inescapável do pluralismo das concepções de bem, os direitos humanos seriam responsáveis por oferecerem à política da comunidade das nações a única base de legitimação reconhecida por todos, dado que praticamente todos os Estados existentes reconhecem a carta 
da ONU, que estaria sendo sempre aperfeiçoada ${ }^{13}$, apesar da validade universal, conteúdo e hierarquia dos direitos humanos nela contidos continuarem sendo, reconhece ele, assunto polêmico (cf. 2001a, p. 151).

A posição habermasiana, nesse ponto, é duramente criticada por vários comentadores, como p. ex. Sergio Costa, que sustenta que, em Habermas, a política transnacional em prol dos direitos humanos adquire fundamentalmente um caráter de antecipação de uma situação futura que essa própria política ajudaria a criar e promover. Além disso, continua Costa (2006, p. 36-7), o exercício de autocrítica realizado pelo autor se restringe somente a reconhecer, na história européia recente, o descentramento da concepção de direitos humanos. Para este autor, Habermas não teria rompido com a representação antinômica entre, de um lado, um centro da sociedade mundial, tratado ora como Ocidente, ora como Europa e definido como precursor e difusor dos direitos humanos; e, de outro, o resto do mundo, receptor dos ideais universalistas europeus.

A visão de uma história social moderna, alerta Costa (p. 39), coloca aquele conjunto de sociedades que se industrializou pioneiramente como um reservatório de valores, instituições e formas de vida que são, numa escala imaginária, mais avançadas ou desenvolvidas. Essa visão deixa de lado a interdependência e simultaneidade entre a modernização material e moral da Europa e as transformações materiais, culturais e morais observadas em outras regiões, no âmbito das empreitadas colonial e escravocrata. A exigência feita pelo autor ao modelo habermasiano consiste em construir parâmetros interculturais que permitam diferenciar formas legítimas, mas que não são passíveis de interpelação discursiva, de estruturas de poder meramente despóticas e opressoras ${ }^{14}$.

Na visão de Costa (37-8), inclusive, justificar uma política mundial em prol dos direitos humanos apresenta inúmeras fragilidades, as quais dificultam

\footnotetext{
${ }^{13}$ Habermas afirma ainda que o discurso dos direitos humanos, diferentemente de outras alternativas, estaria predisposto a dar ouvido a todas as vozes. Por esta razão, ele mesmo se anteciparia, adiantando padrões sob cuja luz até mesmo as infrações latentes contra o próprio pleito em questão podem ser detectadas e corrigidas. "Direitos humanos que promovem a inclusão do outro funcionam ao mesmo tempo como sensores para as exclusões realizadas em seu nome" (2001a, p. 152).

${ }^{14}$ Assim, segundo Costa (2006, p. 44), o desafio que é posto ao modelo habermasiano bem como aos liberais em torno dos direitos humanos consiste em considerar adequadamente formas de autoridade, práticas sociais e aspirações morais que são passíveis de serem reconhecidas como legítimas, mas que não podem e nem devem ser decompostas discursivamente.
}

ENTRE O ANALÍTICO E O PRESCRITIVO...

R. KRITSCH 
a compreensão e legitimação dos anseios cosmopolitas que essa política busca afirmar. A idéia, de que os direitos humanos correspondem a uma "linguagem universal" expressiva das aspirações morais dos cidadãos mundiais, que se encontra além e acima das relações de poder concretas no interior da política mundial, prossegue ele, parece esvaziar as possibilidades analíticas para a compreensão dos paradoxos que cercam os diferentes discursos sobre os direitos humanos e as tensões subjacentes às lutas por sua concretização nos diversos contextos.

Esta posição nos remete, de maneira imediata, ao tema central deste artigo: a dificuldade de se debater direitos humanos quando não se tem clareza a respeito do que é um argumento positivo-descritivo e daquilo que constitui uma asserção normativa-prescritiva em relação aos direitos do homem, além da dificuldade adicional que constitui ter de fazer a crítica aos autores de ambos os pontos de vista, como demonstra o notável esforço de Costa.

\section{BREVES CONSIDERAÇÕES FINAIS}

Como se pode notar, a partir do que foi discutido até aqui, a tensão entre o princípio da soberania estatal nacional e o direito internacional dos direitos humanos não foi superada nem conceitual, nem praticamente. 0 tema continuará a colocar problemas teóricos relevantes, tanto analíticos quanto normativos, em especial no que toca à definição das situações em que a intervenção humanitária pode ser justificada; e no que respeita às instâncias, aos procedimentos e aos critérios adequados para a tomada de decisão e formas de ação a serem adotadas por aqueles que almejam a implementação dos direitos humanos em escala universal.

Reformulações em torno do vínculo entre cidadania democrática, Estado nacional e direitos humanos constitucionalmente garantidos continuam na "pauta do dia" das agendas políticas em várias partes do planeta. Benhabib fala em democratic iterations baseadas num federalismo de tipo cosmopolita; Habermas sugere a noção de patriotismo constitucional numa federação cosmopolita; e assim por diante. Mais do que uma resposta aos problemas que se colocam a todos nós no atual quadro mundial, parece-me, muito mais, que o que nós estamos discutindo, especialmente quando nos debruçamos sobre as teorias normativas-prescritivas da política na contemporaneidade, é o fato de que a atual reconfiguração do sistema de Estados diante do avanço do mundo globalizado constitui uma matéria em plena construção e, por consequiência, em disputa pelas 
várias matrizes teóricas. No entanto, que desenho terá a cidadania e os direitos humanos num quadro futuro, como esse que se afigura, não parece ainda ser possível, por enquanto, prever.

\section{REFERÊNCIAS}

ARCHIBUGI, Daniele. Democracia cosmopolita e seus críticos: uma resenha bibliográfica. Política e Trabalho, João Pessoa, n. 22, 2005, p. 9-48.

ARENDT, Hannah. Origens do Totalitarismo. São Paulo: Companhia das Letras, 1989.

AUDARD, Catherine. Cidadão. In: CANTO-SPERBER, M. (Org.). Dicionário de Ética e Filosofia moral. Vol. 1. São Leopoldo: Ed. Unisinos, 2003.

BARTELSON, Jens. A genealogy of sovereignty. Cambridge: CUP, 1995.

BENHABIB, Seyla. The claims of culture. Princeton: Princeton University Press, 2002.

The rights of others. Cambridge: CUP, 2004.

BODIN, Jean. Les six livres de la Republique. Vol. I. Paris: Fayard, 1986.

. On sovereignty. Ed. by Julian H. Franklin. Cambridge: CUP, 1994.

BROWN, Chris. Universal human rights: a critique. In: DUNNE, Tim; WHEELER, Nicholas J. Human rights in global politics. Cambridge: Cambridge Press, 1999.

COSTA, Sergio. Dois Atlânticos: teoria social, anti-racismo, cosmopolitismo. Ed. UFMG: Minas Gerais, 2006.

DONNELLY, Jack. International Human Rights. $2^{\text {nd }}$ Edition. Boulder Co: Westview Press, 1998.

FORSYTHE, David P. Human rights in international relations. Cambridge: CUP, 2006.

GOYARD-FABRE, Simone. Princípios filosóficos do direito político moderno. São Paulo: Martins Fontes, 2002.

FUKUYAMA, Francis. O fim da bistória e o último homem. Rio de Janeiro: Rocco, 1992. 
HABERMAS, Jürgen. A constelação pós-nacional. São Paulo: Littera Mundi, 2001[a].

.Zeit der Übergänge. [Era das transições]. Frankfurt: Suhrkamp, 2001[b]. . A inclusão do outro. São Paulo: Loyola, 2004.

. Die Einbeziehung des Anderen. [A inclusão do outro]. Frankfurt: Suhrkamp, 1997.

Sobre a legitimação pelos direitos humanos. In: MERLE, Jean-Christophe; MOREIRA, Luiz (org). Direito e legitimidade. São Paulo: Landy Editora, 2003. HELD, David. Democracia, o Estado-Nação e o sistema global. Lua Nova, São Paulo, n. 23, 1991, p. 149-94.

.Democracy and the global order: from the modern state to cosmopolitan governance. New York: Stanford Press, 1995.

Political theory and the modern state. California: Stanford University Press, 1989.

HOBBES, Thomas. Leviathan. Edited by C. B. MacPherson. London: Penguin Books, 1988.

HUNTINGTON, Samuel P. Choque de civilizações. São Paulo: Objetiva, 1997.

IGNATIEFF, Michael. Human Rights as politics and idolatry. New Jersey: Princeton University Press, 2001.

KANT, Immanuel. Zum ewigen Frieden. Sttutgart: Reclam, 1991.

KELSEN, Hans. Teoria geral do direito e do Estado. São Paulo: Martins Fontes, 1990.

KOERNER, Andrei. Ordem política e sujeito de direito no debate sobre direitos humanos. Lua Nova, São Paulo, n. 57, 2002, p.87-111.

KRASNER, Stephen D. Sovereignty - organized hiprocrisy. New Jersey: Princeton University Press, 1999.

KRITSCH, Raquel. Soberania: a construção de um conceito. São Paulo: Humanitas, 2002. . Política e direito: da dupla natureza da noção de soberania. Revista Brasileira de Direito Constitucional, São Paulo, v.6, 2005, p. 375-99. 
PICO DELLA MIRANDOLA, Giovanni. Oratio de hominis dignitate. Tradução Eugenio Garin. Firenze: Vallechi, 1942.

RITTBERGER, Volker. (ed.). Regime Theory and International Relations. 0xford: Clarendon Press, 1993.

STRAYER, Joseph. As origens medievais do Estado moderno. Lisboa, Gradiva, sem data.

WALZER, Michael. Esferas de justiça. São Paulo: Martins Fontes, 2003.

WEBER, Max. Ciência e politica: duas vocações. São Paulo: Cultrix, 1996.

_. Wirtschaft und Gesellschaft. [Economia e sociedade]. Tübingen: Mohr, 1980.

WEBER, Stefan (Hrg.). Theorien der Medien: Von der Kulturkritik bis zum Konstruktivismus. Konstanz: UVK, 2003. 